\title{
Prediction of wintertime heavy snow activity in Northeast China
}

\author{
FAN $\mathrm{Ke}^{1,2^{*}} \&$ TIAN BaoQiang ${ }^{1,3}$ \\ ${ }^{1}$ Nansen-Zhu International Research Center, Institute of Atmospheric Physics, Chinese Academy of Sciences, Beijing 100029, China; \\ ${ }^{2}$ Key Laboratory of Regional Climate-Environment Research for East Asia, Chinese Academy of Sciences, Beijing 100029, China; \\ ${ }^{3}$ Graduate University of the Chinese Academy of Sciences, Beijing 100049, China
}

Received July 5, 2012; accepted September 4, 2012; published online November 7, 2012

\begin{abstract}
In Northeast China during the winter, severe snowstorms can occur resulting in both societal and economic damage. In this paper, we explore an effective technique for the seasonal prediction of heavy snow activity, where previous synoptic studies have failed. We employ a year-to-year increment approach and ultimately identify four predictors, $\mathrm{x}_{1}$ to $\mathrm{x}_{4} \cdot \mathrm{x}_{1}$ is the area-averaged soil moisture over the northern part of Northeast China in the preceding month of September and represents the role of land processes. $\mathrm{x}_{2}$ represents the role of sea-air interactions in winter, $x_{3}$ the preceding summer Mascarene High related to the winter SST over the tropical western Pacific, and $\mathrm{x}_{4}$ is the low-level the thermal condition over Northeast China from the previous year that oppose current year. Cross-validation tests for both 1963-2011 and independent hindcasts between 1983-2010 are performed to validate the prediction ability of our technique. The cross validation test results for 1963-2011 reveal a high correlation coefficient of 0.86 $(0.77)$ between the predicted and observed year-to-year increment of the number of snow days. The model also predicts well the independent hindcast for the years 1983-2011. Therefore, this study provides an effective climate prediction model for Northeast China's heavy snow activities and thus requires preliminary application in operational settings.
\end{abstract}

winter climate, heavy snow, climate prediction

Citation: $\quad$ Fan K, Tian B Q. Prediction of wintertime heavy snow activity in Northeast China. Chin Sci Bull, 2013, 58: 1420-1426, doi: 10.1007/s11434-012-5502-7

Snowstorms that occur in Northeast China during the winter half-year (November to March) have previously caused much societal and economic damage, e.g. that which occurred in Northeast China during March 3-5, 2007 when the strong cold air from the high latitudes meeted the warm air over Northeast China, resulting the record-breaking strong snowfall in that region [1]. Unlike synoptic process studies of snowstorms [2-5] and their climatic characteristics [1,7], climate prediction of snowstorm activity in this region is rare. This is because inter-annual variability of Northeast snowstorm activity and predictive dynamic climate models are ineffective on high latitude climates [8].

In order to resolve such climate prediction difficulties, we developed an inter-annual increment prediction approach $[9,10]$. With our approach the predicted result is a year-to-year increment of a variable (e.g. the difference

*Corresponding author (email: fanke@mail.iap.ac.cn) between the current year and the previous year, abbreviated to DY), rather than its anomalous or its original value. We use the DY of a given variable to represent the Tropospheric Biennial Oscillation (TBO), a feature of East Asian climate, such that the prediction signals are amplified and improve the prediction. However, the DY of the variable also removes its decadal trend, whereas the accumulation of the predicted and DY can reproduce that inter-decadal trend. Importantly, inter-annual increment predictions are based on the previous year's observations rather than those from a varied climatological period. This underlines the effectiveness of prediction from the original or anomalous form to capture the inter-annual and inter-decadal variability. As the prediction of the East Asian mean climate is improved by employing our new approach, the question of validity remains for extreme climate events that undergo large interannual variability creating difficulties in climate prediction. Therefore, based on the variability (DY) of snowstorm days 
over Northeast China, an effective climate prediction scheme are created and verified using a 48-year cross-validation and 28-year independent hindcast procedure.

We derived daily weather data from 750 Chinese meteorological stations which is provided by China Meteorological Adminstration. A monthly atmospheric reanalysis of the data from the National Center for Environmental Prediction and the National Center for Atmospheric Research, with a resolution of $2.5^{\circ} \times 2.5^{\circ}$, is used in our atmosphere circulation analyses. The monthly global soil moisture data (resolution of $0.5^{\circ} \times 0.5^{\circ}$ ), and the monthly global sea surface temperature (resolution $2.5^{\circ} \times 2.5^{\circ}$ ), are provided by National Oceanic and Atmospheric Administration. Niño34 index is denoted by the area-averaged sea surface temperature anomaly over $170^{\circ}-120^{\circ} \mathrm{W}, 5^{\circ} \mathrm{S}-5^{\circ} \mathrm{N}$. All of these data cover the period between 1961-2011. To date, Northeast China is covered by 96 weather stations that include Heilongjiang Province, Liaoning Province and east of Inner Mongolia Autonomous Region (Figure 1(a)). A snowstorm day at any station is defined as a day when the surface temperature is lower than $0^{\circ} \mathrm{C}$ and when the daily snowfall amount is greater than $5 \mathrm{~mm} \mathrm{[6].} \mathrm{The} \mathrm{number} \mathrm{of} \mathrm{snowstorm}$ days (NSD) refers to the total number of snowstorm days for each of the 96 stations during November-March. Figure 1(b) shows that the NSD undergoes a large interannual variability without a significant decadal trend, which is consistent with the findings of [6].
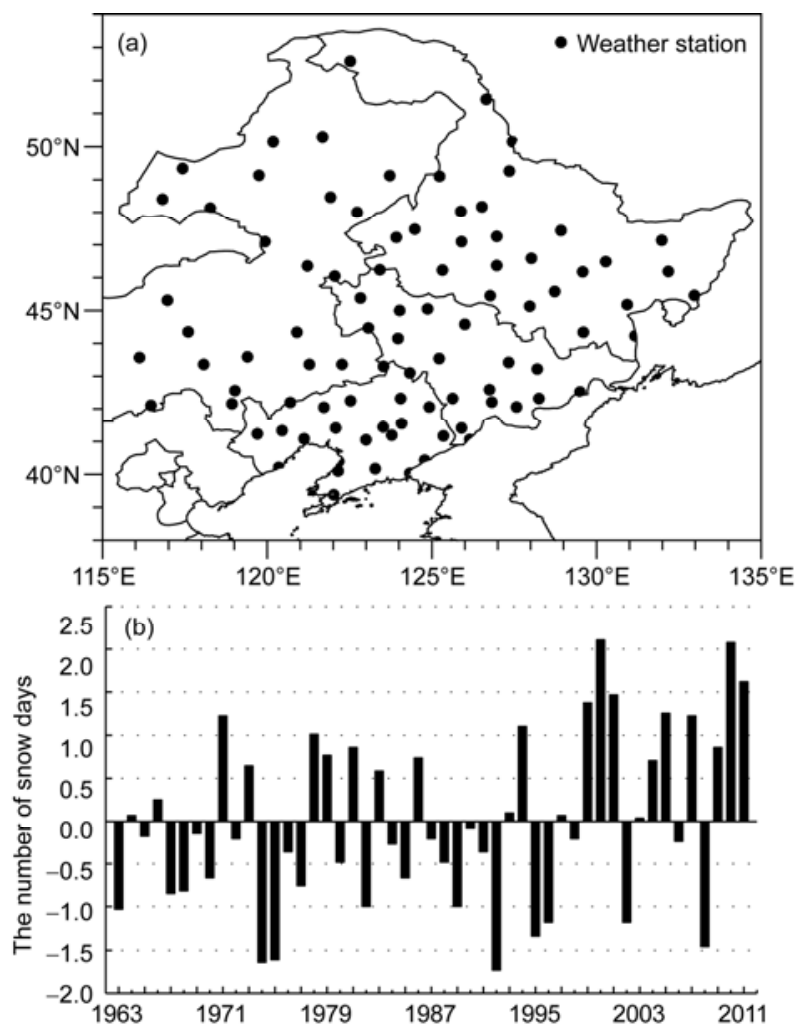

Figure 1 (a) The spatial weather stations over Northeast China; (b) the normalized NSD time series during 1963-2001.

\section{The circulation DY associated with the NSD and predictors}

There are two conditions necessary for snowstorms. One is that the surface temperature must be lower than $0^{\circ} \mathrm{C}$ indicating the influence of strong cold air activity. The other is that warm and moist air conditions over Northeast China must be present. Therefore we investigated the DY of circulation which is related to the DY of the NSD during the winter half-year. A negative North Atlantic Oscillation is associated with the NSD DY at the $1000 \mathrm{hPa}$ wind field. This is characterized by an anticyclonic anomaly over Eurasia at high latitudes and a cyclonic anomaly between Lake Balkhash and Lake Baikal along with an easterly anomaly at $60^{\circ} \mathrm{N}$. These anomalies enhance the cold air activity and increase the frequency of cyclones over northern China during winter and spring [11-13]. Of interest is the anomalous northerly wind in front of an anticyclonic anomaly over Yakutsk (Figure 2(a)). This feature brings cold air from the polar regions into Northeast China. A positive North Pacific Oscillation, concurrent with a cyclonic anomaly over the Bering Sea and an anticyclonic anomaly over the middle North Pacific, suggests a reinforcement of the Aleutian Low and North Pacific High. The anomalous southeasterlies from the western edge of the reinforced North Pacific High (Figure 2(a)) can increase the warm and moist air transport toward Northeast China. Additionally, a warm and moist air stream from the tropical ocean toward Northeast China is caused by anomalous southerlies along the East Asian coast. Two branches of southerlies subsequently cause abundant water vapor over Northeast China that result in high frequency of NSD during the winter half-year. Correspondingly, two centers of the vertical integrated water vapor content for the whole troposphere (1000-300 hPa) extend from the South Sea to the tropical western Pacific and expand from Northeast Asia to the North Pacific, respectively (Figure 2(b)). It was noted that the center of formation of the vertical integrated water vapor coincides with the maximum center of positive temperature anomalies at $1000 \mathrm{hPa}$ (Figure 2(c)). As such, the frontogenesis that provides the dynamical conditions for a high NSD frequency could be formed over Northeast China.

Based on the inter-annual variability of NSD DY and its association with the atmospheric circulation DY during the winter half-year, the predictors for the NSD DY can be identified. These predictors not only should have a statistical relationship with the NSD DY, but they should also reflect the physical processes.

One of these predictors is soil moisture, an important variable for land surface processes and which plays a critical role in climate change via the transport of latent heat, sensible heat flux and momentum exchange between the soil and atmosphere. These processes are induced by the surface albedo and surface heat capacity that vary with the soil moisture. Therefore, the soil moisture has a physical connection 


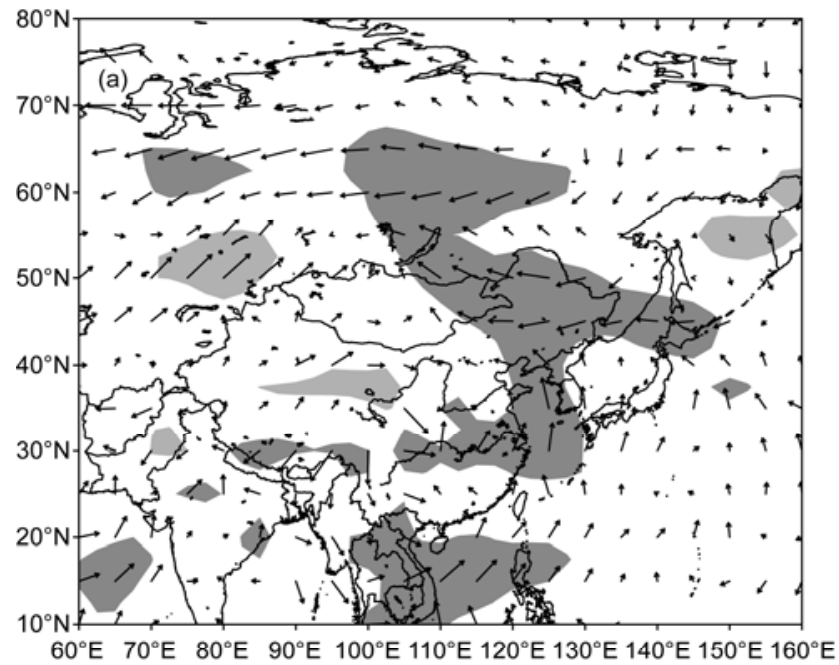

$\overrightarrow{0.7}$
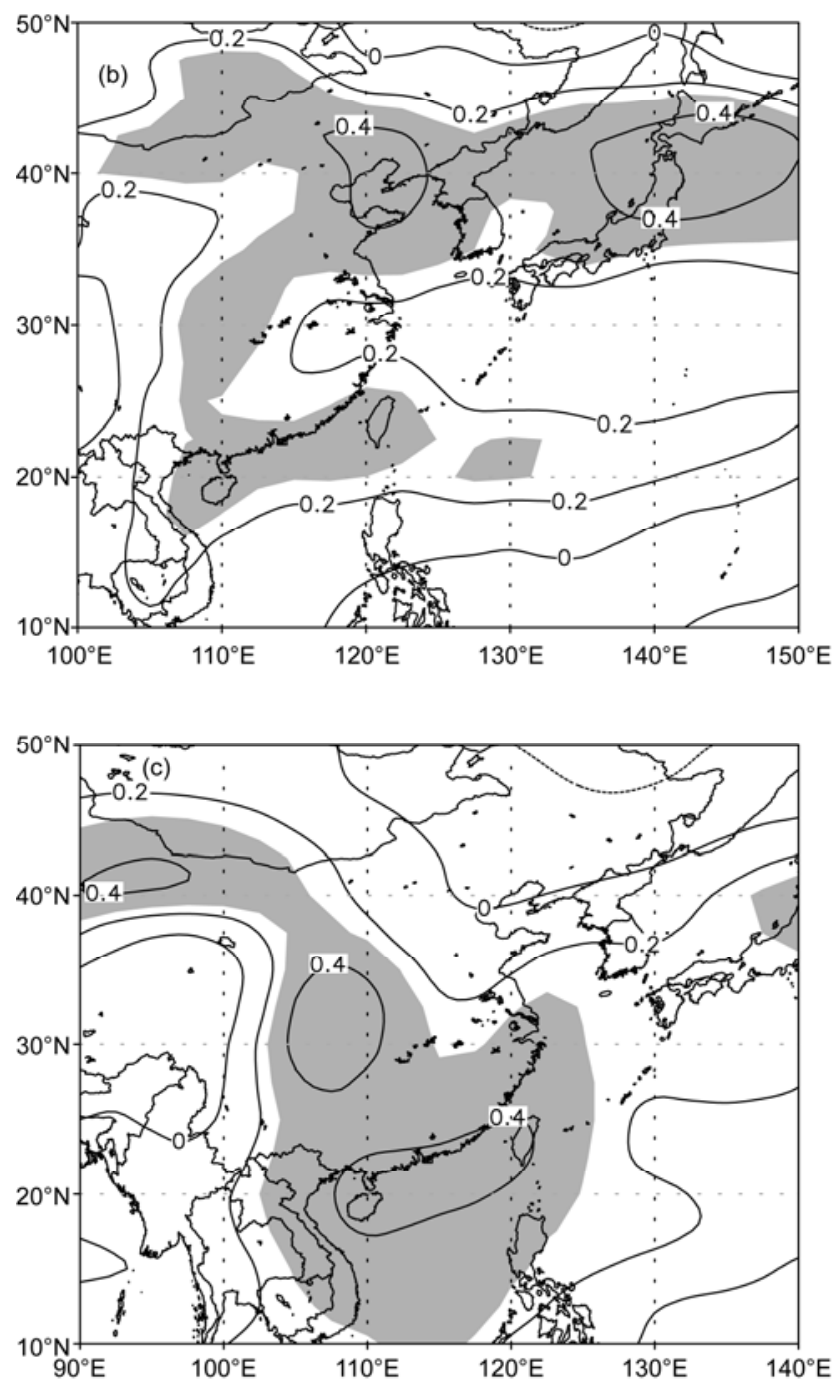

Figure 2 The correlation coefficients of NSD DY and circulation DY for the winter half-year. (a) DY of $1000 \mathrm{hPa}$ wind; (b) the vertical integrated water vapor content in the $1000-300 \mathrm{hPa}$; (c) DY of $1000 \mathrm{hPa}$ temperature. The shaded areas indicate a significant level above 0.05 using a $t$-test. to the air temperature. Along with the sea surface temperature, the soil moisture is significant in climate prediction because of its good memory of anomalous climate [14-16].

We found that an increase of soil moisture DY over northern Northeast China in a preceding September tends to increase the NSD DY in the winter half-year (Figure 3(a)). The index of soil moisture (ISM) is therefore defined by the area-averaged soil moisture over $122^{\circ}-128^{\circ} \mathrm{E}, 48^{\circ}-55.25^{\circ} \mathrm{N}$. The ISM and NSD between 1963-2009 are highly correlated, with a correlation coefficient of 0.51 , above the 0.01 significance level. One question we asked is how the ISM in a preceding September would impact the NSD. We found that an increase of the ISM DY tended to increase the sea level pressure over Yakutsk for the winter half-year, which is a key system leading cold air from the polar regions toward Northeast China (Figures 2(a) and 3(b)).
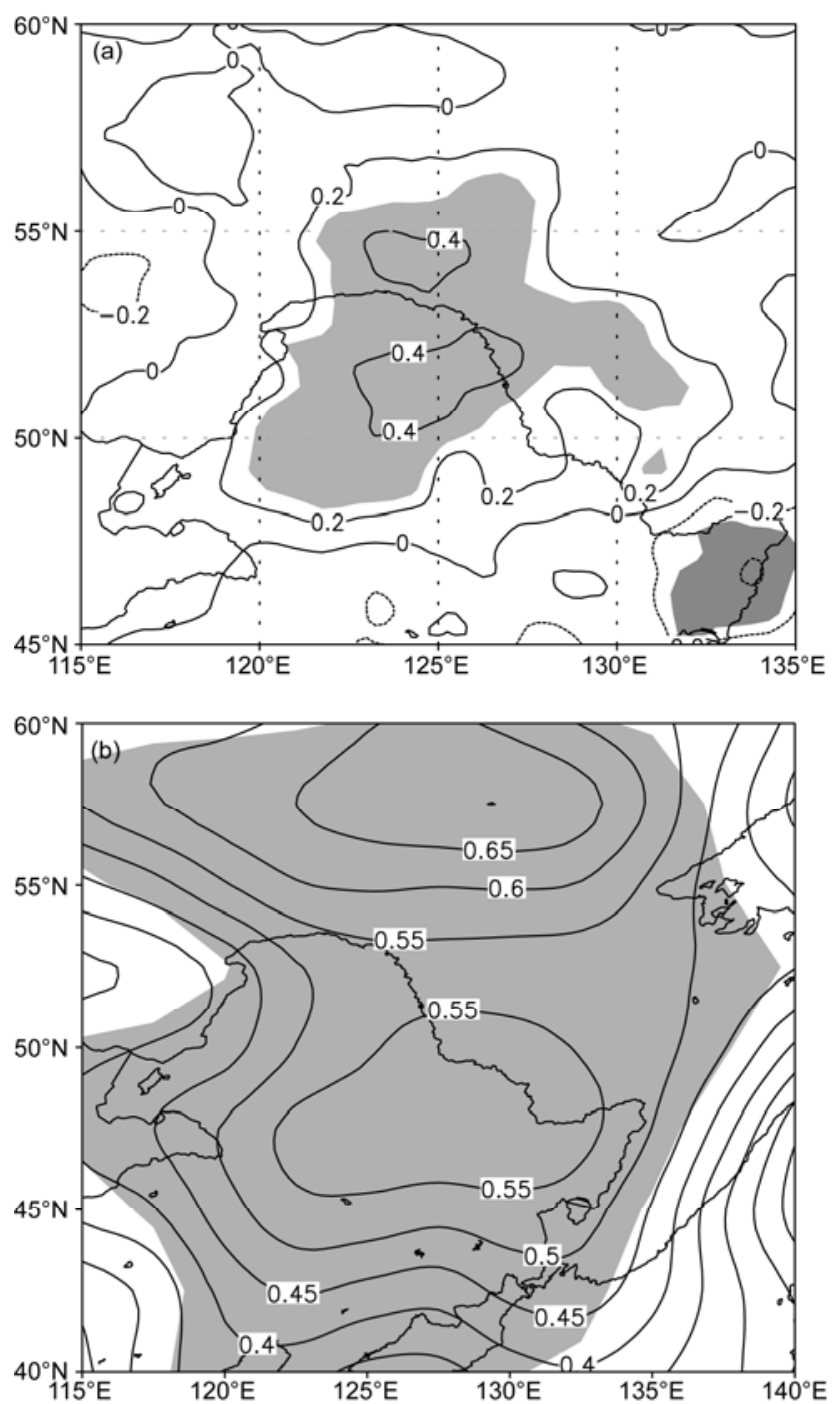

Figure 3 The analysis of the predictor of $x_{1}$. (a) Correlation coefficient pattern of the preceding September soil moisture DY and the NSD DY; (b) linear regression pattern of the winter half-year SLP DY based on $\mathrm{x}_{1}$. The shaded areas indicate a significant level above 0.05 according to $t$-test results. 
In operational predictions, the preceding anomalous sea surface temperatures (SSTs) over a key region are considered as a prediction signal for climate change. For example, SST anomalies over the tropical eastern Pacific, an ocean with a small specific heat and large heat capacity store anomalous climate signals that further impact the climate sea-air interaction processes. This too, is considered a variable in our model.

The preceding anomalous sea surface temperatures (SSTs) show a correlation coefficient between the DY of SSTs in boreal winter (December-January-February) and the DY of NSD in Figure 4(a). This figure shows a tripolar anomaly pattern of the SST's DY over the North Pacific, with positive anomalous DY of SST over the South Sea and East Asia, negative anomalous values over the western North Pacific and positive anomalous values over the eastern North Pacific. As there is an insignificant correlation coefficient (0.11) between the Niño34 SST index in winter and the NSD between 1963-2009, this tripolar anomaly of SSTs (Figure 4(a)) is not a typical ENSO pattern.

The anomalous tripolar DY of the SSTs related to the winter half-year NSD DY occurred early in the preceding
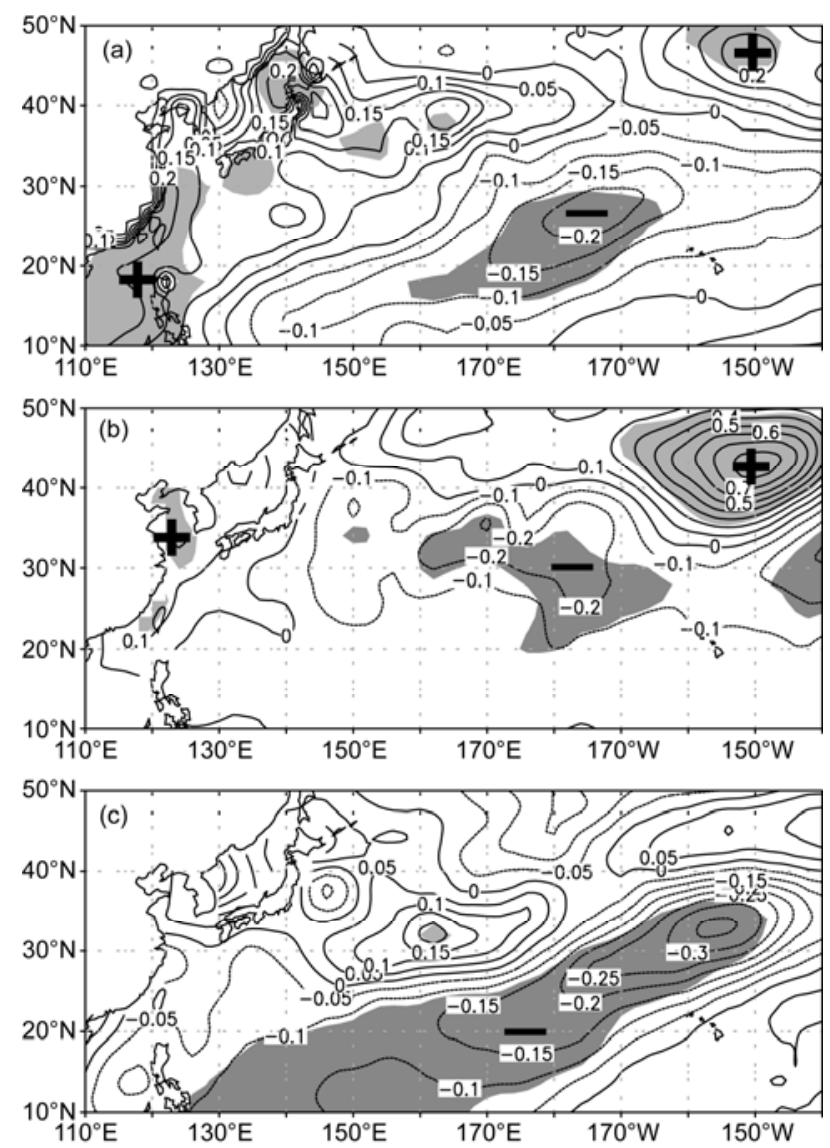

Figure 4 The analysis of the predictor of $x_{2}$ and $x_{3}$. (a) Correlation coefficients between the NSD DY and winter SSTs DY. (b) The preceding September to October SSTs regressed onto the $\mathrm{x}_{2}$ predictor. (c) The preceding summer SSTs DY regressed onto the $\mathrm{x}_{3}$ predictor. The shaded areas indicate a significant level above 0.05 by the $t$-test.
September-October. Therefore, the area-mean DY of zonal wind over $150^{\circ}-120^{\circ} \mathrm{W}, 60^{\circ}-75^{\circ} \mathrm{N}$ in the preceding September-October is selected as the second predictor $\mathrm{x}_{2}$ for the NSD DY. This second predictor shows that the tripolar DY of SSTs over the North Pacific is related, with a significant correlation coefficient of 0.69 between the NSD DY and $x_{2}$ during 1963-2009, above the 0.01 significance level (Figure 4(b)).

Previous findings have indicated that as the summer Mascarene High intensifies, the Australian High is also intensified via energy dispersion by westerlies [17]. In addition, the cross equatorial flow over Indonesia that is associated with the Australian High is subsequently enhanced, whereas the tropical trade winds are weakened. As a result, tropical convection over the east of the Philippines becomes weaker and induces the reinforcement of the Western North Pacific Subtropical High and a southward shift [18-21]. Therefore, the preceding summer Mascarene High was another variable in our model and the third predictor, $\mathrm{x}_{3}$ of the NSD DY represents the preceding summer Mascarene High (June-July-August) and is defined as the area-mean DY of SLP over the subtropical Indian Ocean in the preceding summer. This third predictor shows a significant correlation coefficient of 0.46 at the 0.05 significance level between $\mathrm{x}_{3}$ and the NSD DY. Figure 4(c) shows that the Mascarene High DY is negatively correlated with the SST DY over the tropical western North Pacific in the preceding summer and that this can persist into winter (Figure 4(a)).

In addition, the NSD DY of the current year has a negative correlation with NSD DY from the previous year due to the NSD's 2-year or 4-year cycle with a correlation coefficient of -0.4 , above the 0.05 significance level. A fourth predictor was the circulation related to the NSD DY from the previous year. This was is defined as the area-mean temperature DY at $850 \mathrm{hPa}\left(105^{\circ}-120^{\circ} \mathrm{E}, 20^{\circ}-35^{\circ} \mathrm{N}\right)$, a correlation coefficient of -0.4 at the 0.05 significance level between $\mathrm{x}_{4}$ and the NSD DY.

\section{Prediction model and validation}

The prediction model for the NSD DY is established using a multi-linear regression method containing our four predictors. A cross-validation test for the period of 1965-2011 (48 years) and independent hindcasts for the years 1983-2011 (28 years) are performed to avoid over-fitting the prediction model and to obtain more independent samples. The cross validation test for the 1965-2011 period can be applied by removing each year, one at a time, from the training set and generating a new set of coefficients based on the remaining years. This process can then be repeated to generate blind forecasts for each year for the entire data set. In this way, we obtain 48 prediction models whose predictors are tested during different years with more independent prediction samples (48 years). To further verify the prediction model, 
we make an independent hindcast for the years 1983-2011 (28 years), similar to the real forecast. For instance, we use the 1963-1982 dataset to forecast the 1983 values, the 1963-1984 dataset to predict the 1983 values, and the 1963-2010 dataset to predict the 2010 values.

The results from the predicted NSD DY derived from the cross-validation test for 1963-2011 are shown in Figure 5(a). The NSD DY also exhibits a large inter-annual variability. For instance, abrupt changes occurred within the years 1973-1974, 1981-1984, 1992-1995, and 2002-2011. The prediction model appears to capture these abrupt NSD DY changes. The correlation coefficient between the predicted and observed NSD DY during 1963-2001, derived by our cross-validation test was 0.86 . This accounts for $74 \%$ of the total variance of observed the NSD DY. We obtain the predicted NSD by adding the predicted NSD DY to the observed NSD during the previous year, and the predicted percentage of NSD anomalies (Figure 5(b)). The predicted percentage of NSD anomalies is consistent with the observed values from year to year, with a correlation coeffi- cient of 0.77 and a high rate of coherence of $96 \%$, excluding the two years of 2000 and 2001.

The prediction scheme also shows good predictive ability in the independent hindcasts for 1984-2011. These hindcasts have a correlation coefficient of 0.80 between the predicted and observed NSD DY, accounting for $64 \%$ of the total variance of the observed NSD DY and a low root mean square error of $24 \%$ (Figure 6).

\section{Discussion and conclusions}

From our model we speculate that the physical positive feedback processes between the NSD and ISM that result from the ISM increase might be explained as the increase of evapotranspiration and a decrease in sensible heat flux resulting in a lower surface air temperature. This would in turn create early occurrences of snow and an extension of the snow cover that could further increase the surface albedo and decrease the surface air temperature. This cold surface
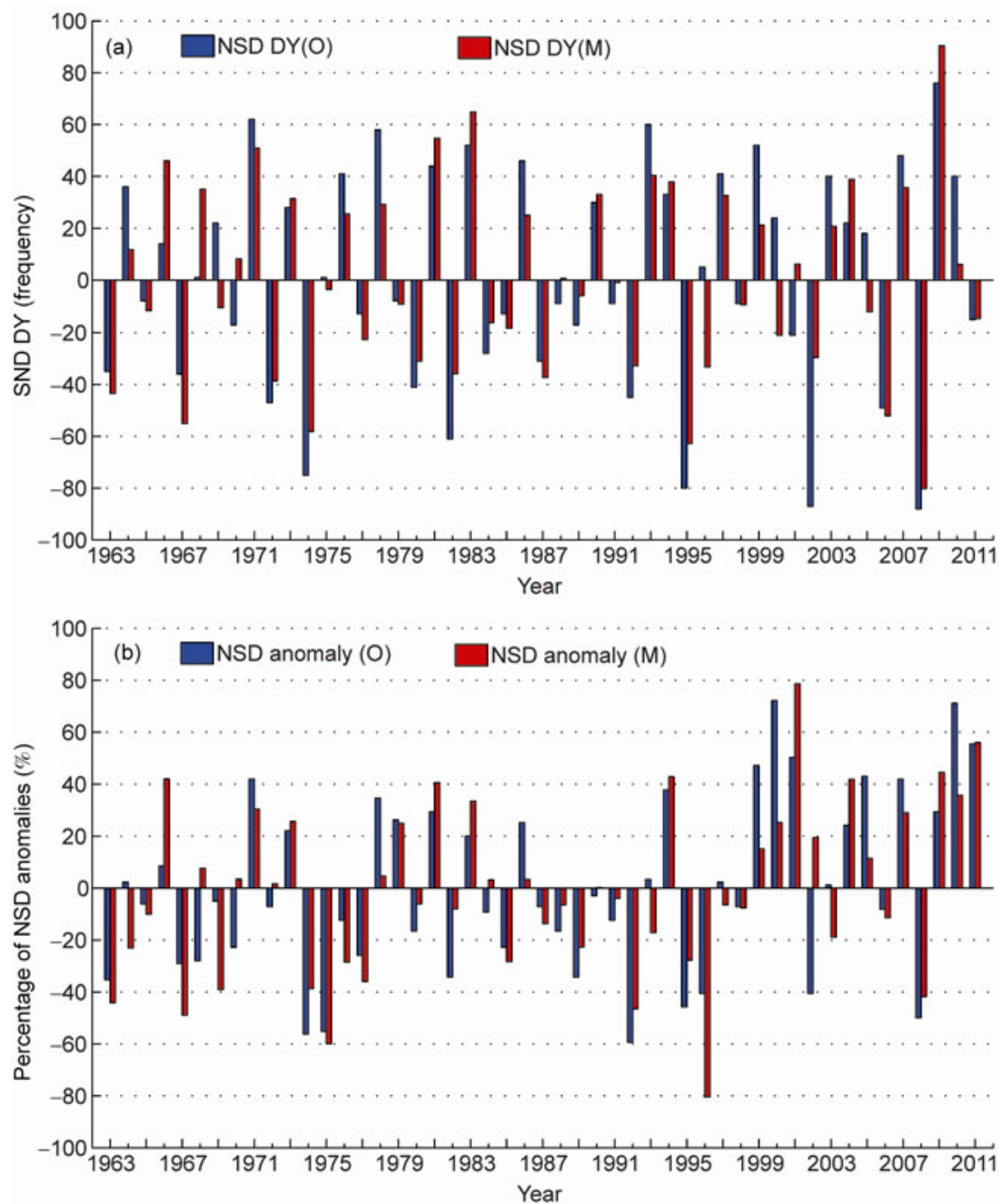

Figure 5 (a) Predicted NSD DY (red) and observed NSD DY (blue) in the cross-validation test for the 1963-2011 period. (b) Predicted percentage of NSD anomalies (red) and observed percentage of NSD anomalies (blue) in the cross-validation test for the 1963-2011 period. 

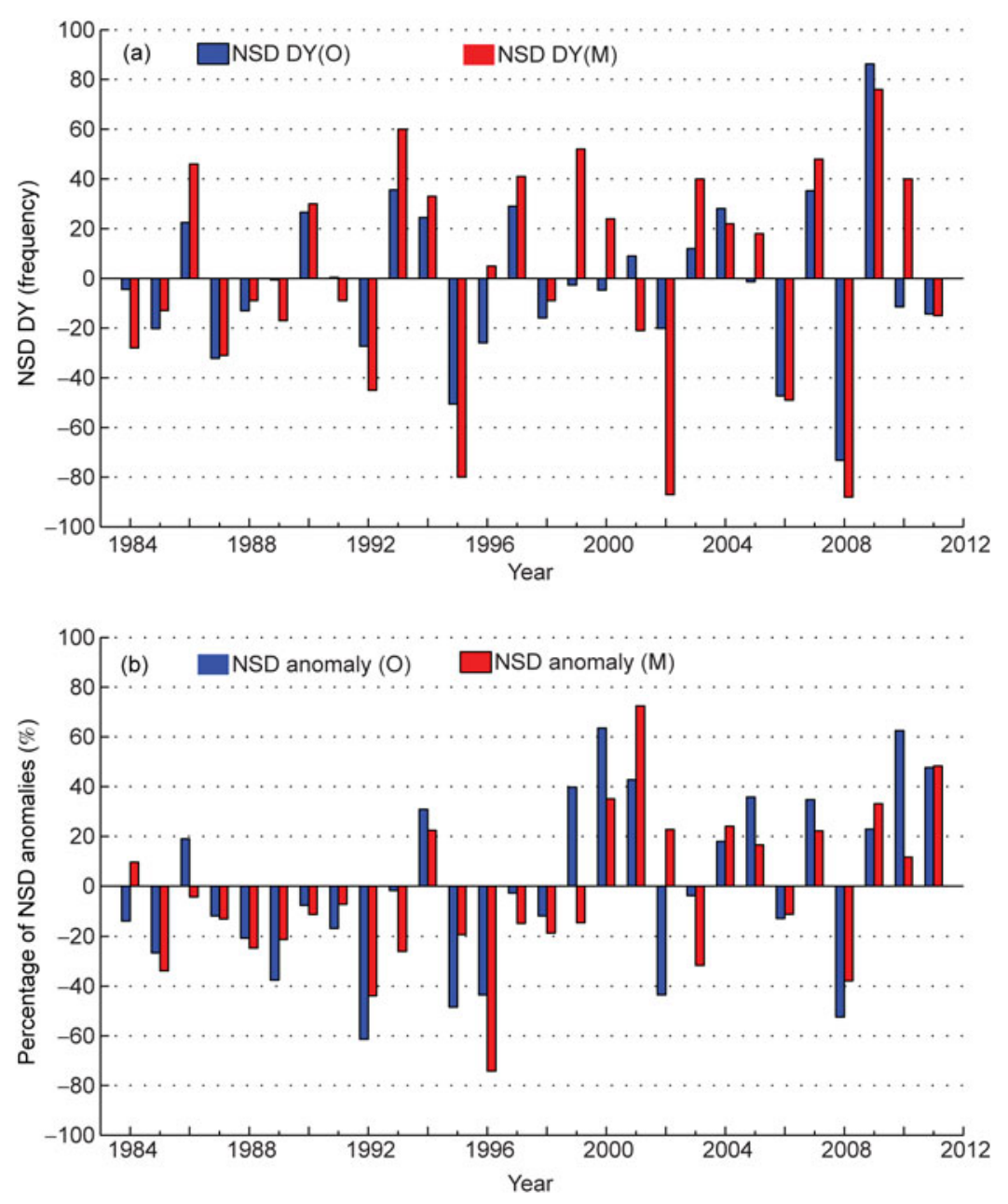

Figure 6 (a) Predicted NSD DY (red) and observed NSD DY (blue) in independent hindcasts for the 1984-2011 period; (b) predicted percentage of NSD anomalies (red) and observed percentage of NSD anomalies (blue) in independent hindcasts for the 1984-2011 period.

could then contribute to the rise in the sea level pressure over Yakutsk. Therefore, the ISM in the preceding September is identified as the first predictor.

We show that the preceding summer Mascarene High $\left(\mathrm{x}_{3}\right)$ and the NSD DY has a statistically significant correlation, suggesting a physical connection to the NSD DY in the winter half-year via the SST DY over the tropical western North Pacific persisting from the preceding summer to the winter half-year. However, the lack of correlation between the Niño34 in winter and the NSD (1963-2009) we interpret as an interaction of a winter monsoon and the SSTs over the North Pacific. As previous results indicated [21-25], the cold and dry air advection in winter caused by reinforced anomalous northerlies over the East Asian coast lead to a large local temperature difference between the sea surface and atmosphere; the atmosphere over this region is heated, whereas the related SST is decreased. This temperature difference is responsible for the deepened Aleutian Low and shifts it southward due to the strong baroclinicity and active convection in the atmosphere. However, the deepened Aleutian Low can intensify the cold air activity, which fur- ther increases the heat exchange between the ocean and atmosphere to decrease the SST over the East Asian coast via this positive feedback process of the sea and winter monsoon. In addition, the increased sensible heat flux, along with the increase in SSTs over the tropical western North Pacific warm pool, intensifies the local Hadley Circulation associated with the northerlies over the East Asian coast [25].

A large inter-annual variability of NSD and the ineffective prediction for climate at high latitudes can contribute to difficulties in climate prediction. Based on the inter-annual variability of the NSD DY from our study, and their association with the DY of circulations and their physical processes, four predictors were identified. (1) The soil moisture DY over northern Northeast China in the preceding September, (2) the DY of zonal winds at high latitude over the North Pacific in the preceding September-October, (3) the preceding summer Mascarene High DY, and (4) the temperature DY at low levels over southern China in the previous winter half-year. These predictions are established for the NSD DY. The predicted NSD is obtained by adding the 
predicted NSD DY to the observed NSD from the previous year. Our predicted NSD DY derived from the cross-validation test for 1963-2011 (48 years) show that the TBO feature of the NSD is captured by NSD DY, as a positive NSD DY from the previous year is followed by a negative NSD DY in the current year and subsequently a positive value for the next year. Our prediction scheme proves effective for both the NSD DY and the NDS in two validation methods.

We also found that the NSD prediction signals are not as significant as those of the NSD DY, such as the soil moisture over northern Northeast China and the SSTs over the North Pacific. These both involve critical land processes and sea-air interactions and hinder the direct predicting of NSD. In contrast, predictors of the NSD DY and the above physical processes are identified owing to the amplified prediction signals from employing an inter-annual increment approach.

Although this study provides an effective climate prediction model for heavy snow activity in Northeast China, it requires testing in an operational setting. The climate causes and physical processes should be further investigated and new extreme climate prediction approaches combining dynamical and statistical models should be developed in the future [26].

This work was supported by the National Basic Research Program of China (2009CB421406), the Knowledge Innovation Key Program of the Chinese Academy of Sciences (KZCX2-YW-QN202), and Strategic Technological Program of Chinese Academy of Sciences (XDA05090426).

1 Sun J Q, Wang H J, Yuan W A. preliminary investigation on causes of the catastrophic snowstorm in March, 2007 in the northeastern parts of China (in Chinese). Acta Meteorol Sin, 2009, 67: 469-477

2 Wang $\mathrm{W} \mathrm{H}, \mathrm{Xu}$ X D. The heavy snow process in district xilingele and the analysis of "77.10" snowstorm (in Chinese). Acta Meteorol Sin, 1979, 37: 80-86

3 Wang J Z, Ding Y H. Research of moist symmetric instability in a strong snowfall in North China (in Chinese). Acta Meteorol Sin, 1995, 53: 451-460

4 Wang H J, Yu E T, Yang S. An exceptionally heavy snowfall in Northeast China: Large-scale circulation anomalies and hindcast of the NCAR WRF model. Meteorol Atmos Phys, 2011, 113: 11-25

5 Gao Y Z, Zhou H L, Yun C Q, et al. Weather analysis and prediction technology of snowstorm in Heilongjiang Province (in Chinese). J Nat Disasters, 2007, 16: 25-30

6 Sun J Q, Wang H J, Yuan W, et al. Spatial-temporal features of intense snowfall events in China and their possible change. J Geophys Res, 2010, 115: D16110

7 Liu Y L, Yu H M, Reng Y, et al. Temporal and spatial variation characteristics of the snow storms in Heilongjiang Province during 1961-2006 (in Chinese). Clim Environ Res, 2010, 15: 470-478

8 Gao X J, Zhao Z C, Ding Y H, et al. Climate change due to greenhouse effects in China as simulated by a regional climate model. Adv Atmos Sci, 2001, 18: 1224-1230

9 Fan K, Wang H J, Choi Y J. A physically-based statistical forecast model for the middle-lower reaches of the Yangtze River Valley summer rainfall. Chin Sci Bull, 2008, 53: 602-609

10 Fan K, Wang H J. Seasonal prediction of summer temperature over Northeast China using a year-to-year incremental approach. Acta Meteorol Sin, 2010, 24: 269-275

11 Wu B Y, Huang R H. Effects of the extremes in the North Atlantic Oscillation on East Asia winter monsoon (in Chinese). Chin J Atmos Sci, 1999, 23: 642-651

12 Fan K, Wang H J. Antarctic oscillation and the dust weather frequency in North China. Geophys Res Lett, 2004, 31: L10201

13 Fan K, Wang H J. Interannual variability of Antarctic Oscillation and its influence on East Asian climate during winter and spring. Sci China Ser D-Earth Sci, 2006, 49: 554-560

14 Wang W Q. Numerical experiments of the soil temperature and moisture anomalies effects on the short term climate (in Chinese). Chin J Atmos Sci, 1991, 15: 56-63

15 Ma Z G, Wei H L, Fu C B. Relationship between regional soil moisture variation and climatic variability over east China (in Chinese). Acta Meteorol Sin, 2000, 58: 278-286

16 Guo W D, Ma Z G, Wang H J. Soil moisture-An important factor of seasonal precipitation prediction and its application (in Chinese). Clim Environ Res, 2007, 12: 21-28

17 Xue F, Wang H J, He J H. Interannual variability of Mascarene high and Australian high and their influences on East Asian summer monsoon. J Meteorol Soc Jpn, 2004, 82: 1173-1186

18 Sun J Q, Wang H J, Yuan W. Linkage of the Boreal Spring Antarctic Oscillation to the West African Summer Monsoon. J Meteorol Soc Jpn, 2010, 88: 15-28

19 Zhou B T. Linkage between winter sea surface temperature east of Australia and summer precipitation in the Yangtze River valley and a possible physical mechanism. Chin Sci Bull, 2011, 56: 1821-1827

20 Gao H, Xue F, Wang H J. Influence of interannual variability of Antarctic oscillation on Mei-yu along the Yangtze and Huaihe River valley and its importance to prediction. Chin Sci Bull, 2003, 48: 61-67

21 Wang H J, Fan K. Central-north China precipitation as reconstructed from the Qing dynasty: Signal of the Antarctic Atmospheric Oscillation. Geophys Res Lett, 2005, 32: L24705

22 Zhao Y P, McBean G A. Air-sea interaction between the kuroshio region marine heating anomaly and northern hemisphere atmospheric circulation (in Chinese). Oceanol Limnol Sin, 1995, 26: 386-387

23 Chen J, Sun S Q. Eastern Asian Winter Monsoon Anomaly and Variation of Global Circulation Part II: Influence on SST by Winter Monsoon (in Chinese). Chin J Atmos Sci, 1999, 23: 286-295

24 Qing Z K, Sun Z B. Numerical simulation of the influence of successively anomalous winter wind field on ocean currents around the Kuroshio area (in Chinese). Chin J Atmos Sci, 2006, 30: 257-267

25 Dong M, Chen L X, Liao H. Numerical simulation of the influence of SST anomaly over western Pacific warm pool on winter circulations (in Chinese). Acta Oceanol Sin, 1994, 16: 39-45

26 Wang H J, Sun J Q, Chen H P, et al. Extreme Climate in China: Facts, Simulation and Projection. Meteorol Zeitschrift, 2012, doi: 10.1127/ 0941-2948/2012/0330

Open Access This article is distributed under the terms of the Creative Commons Attribution License which permits any use, distribution, and reproduction in any medium, provided the original author(s) and source are credited. 